\title{
Provider perspectives on presenting risk information and managing worry about recurrence among breast cancer survivors
}

\author{
Nancy K. Janz '*, Rebecca L. Leinberger', Brian J. Zikmund-Fisher ${ }^{1,2}$, Sarah T. Hawley ${ }^{2,3}$, Kent Griffith ${ }^{4}$ and Reshma Jagsi ${ }^{5}$ \\ 'Department of Health Behavior and Health Education, School of Public Health, University of Michigan, Ann Arbor, MI, USA \\ ${ }^{2}$ Internal Medicine-General Medicine, University of Michigan, Ann Arbor, MI, USA \\ ${ }^{3}$ Ann Arbor VA Medical Center, Ann Arbor, MI, USA \\ ${ }^{4}$ Center for Cancer Biostatistics, School of Public Health, University of Michigan, Ann Arbor, MI, USA \\ ${ }^{5}$ Department of Radiation Oncology, University of Michigan, Ann Arbor, MI, USA
}

*Correspondence to:

Department of Health Behavior

and Health Education, University

of Michigan, School of Public

Health, 1415 Washington

Heights, Ann Arbor, MI, USA.

E-mail: nkjanz@umich.edu

Received: 20 December 2013

Revised: 25 June 2014

Accepted: 30 June 2014

\begin{abstract}
Background: Although worry about recurrence is a persistent concern among breast cancer survivors, little is known about physicians' confidence about presenting recurrence risk information, identifying women with considerable worry, and helping women manage worry.

Methods: Between January and June 2012, we surveyed 750 surgeons and 750 medical oncologists randomly sampled from the American Medical Association Physician Masterfile. We tested differences between surgeons and medical oncologists on confidence of presenting risk, identifying and managing worry using chi-square statistic and Student's $t$-tests and developed multiple variable logistic regression models to explain odds regarding confidence and use of different strategies for managing worry.

Results: The analytic sample included 403 surgeons and 363 medical oncologists $(n=766$; response rate $\mathbf{6 0} \%$ ). Compared with surgeons, medical oncologists were significantly more likely to report confidence in: presenting risk information $(87.5 \%$ vs $\mathbf{7 3 . 2 \%})$, identifying women who are worried $\mathbf{7 4 . 1 \%}$ vs $63.9 \%)$, and managing worry $(66.9 \%$ vs $52.4 \%)$. Confidence in managing worry was associated with more regular inquiry about worry $(p=0.009)$. Models of the likelihood of using different management strategies varied by provider type (e.g., surgeons more likely than medical oncologists to recommend support group or online resources, oncologists more likely to refer to psychologist or use medications, all $p<0.05)$.

Conclusion: Cancer providers, particularly surgeons, may benefit from educational training to raise confidence in identifying women with high levels of worry and managing women with considerable worry. Communication between specialties and primary care physicians on efforts to manage worry is necessary for coordinated, quality care for women with breast cancer.

Copyright () 2014 John Wiley \& Sons, Ltd.
\end{abstract}

\section{Introduction}

Considerable research has documented that worry about recurrence is a major concern among women with breast cancer in the survivorship period [1-7]. A recent review of studies of long-term cancer survivors concluded that modestly intense fear of recurrence is experienced by most long-term survivors [8]. Most studies to date have focused on the patients' perceptions about recurrence risk and the potential negative consequences of excessive worry on decision-making, surveillance behaviors and quality of life [9-12], with significant negative associations between considerable worry, and psychological distress and quality of life [7]. Far less attention has been focused on how confident providers of cancer care are at presenting risk information, identifying women with considerable worry, and assisting women to manage worry about recurrence over time.
The Institute of Medicine has stated that psychosocial care is integral to quality survivorship care [13]. Indeed, studies that have focused on provider perceptions generally find that physicians caring for women with breast cancer consider addressing psychosocial concerns to be part of their responsibility [14-17]. Some attention has been devoted to developing online tools and other resources to assist physicians in presenting risk information to their breast cancer patients [18-22], although most communications of recurrence risk have focused on improving treatment decision-making more than clarifying risk of recurrence itself.

In order to address the psychosocial needs of cancer survivors, physicians need to routinely assess mental health concerns of their patients and refer to appropriate mental health professionals as needed. Cancer survivors whose mental health concerns are addressed report greater satisfaction with the quality of their care [23]. Previous 
studies have suggested that physicians tend to underestimate the level of depressive symptoms in patients and may be unaware of the importance of assessing the more reliable symptoms of mental health distress [24-26]. Despite the demonstrated need for mental health support, a recent population-based survey found that less than half of the cancer survivors reported that they discussed the psychological effects of cancer with their physician and/ or were referred to mental health specialists or support groups [23].

In addition to identifying women with elevated levels of worry about recurrence, better strategies to help these women manage their worry are also needed. A variety of approaches or strategies are available to help women manage worry ranging from information sources in print or online formats, support groups or peer counseling, referrals to other professionals, including mental health care providers, and/or the use of medicines or alternative therapies. A systematic review of the literature found that cancer patients with fulfilled information need experience less anxiety and depression [27]. Very few studies have assessed the frequency of use of these strategies to assist women coping with their worry [28], and even fewer have examined if provider characteristics or the practice setting influences the kinds of resources employed.

How confident cancer care providers are in presenting risk information, inquiring about worry about recurrence and suggesting strategies to manage worry, or the extent to which there is variation across provider type has not received sufficient research attention. Both surgeons and medical oncologists routinely present risk information during the treatment decision-making phase and provide ongoing follow-up care to women with breast cancer. A positive relationship between physician confidence and competence has been demonstrated in previous studies [29,30]. For example, in a nationally representative survey of primary care physicians and medical oncologists, physicians with greater confidence in their knowledge about possible adverse psychosocial outcomes were more likely to engage in psychosocial care of their patients [30]. A greater understanding of physicians' attitudes and behaviors regarding worry about recurrence in breast cancer could help women make informed treatment decisions rather than decisions based on unfounded fears. In addition, knowing how physicians' approach to managing worry about recurrence during the survivorship period could lead to greater understanding of common approaches employed, areas where additional training or skill building may be helpful, and system and resource barriers that may inhibit providing coordinated quality cancer care to women in the survivorship period.

To address these gaps in the literature, we evaluated physicians' self-reported confidence in presenting risk information as well as in identifying women with high levels of worry and managing worry about recurrence in a randomly selected sample of medical oncologists and surgeons caring for women with breast cancer. We paid particular attention to whether these factors differed by specialty. We further sought to identify the frequency with which these providers utilize various potential strategies for managing worry about recurrence, as well as provider characteristics that correspond with use of different management approaches.

\section{Methods}

\section{Sampling and data collection}

Our sample was drawn from the American Medical Association Physician Masterfile (MF), a reasonably comprehensive list of US physicians, amassed on the basis of medical school and residency enrollment and licensing records. We obtained a randomly selected sample of physicians whose specialty was medical oncology or hematology/oncology, or surgery or surgical oncology, along with their contact information. Prior to survey mailing, we telephoned to confirm addresses and to eliminate subjects whose practices clearly excluded breast cancer. We originally randomly sampled 750 surgeons and medical oncologists from the MF. We then called practice to confirm treatment of breast cancer patients. Those not treating breast cancer patients were excluded. Afterward, another random sample was selected from the MF list equal to the number excluded. The process iterated such that three different random samples were chosen until we reached 750 mailed per group that we reasonably believed at the time of mailing treated breast cancer patients.

Between January and June 2012, we mailed 750 surgeons and 750 medical oncologists a questionnaire and a $\$ 50$ cash incentive. We utilized a modified Dillman approach, including follow-up with nonresponders, to maximize response rate [31]. The survey asked potential participants whether they had seen at least one new breast cancer patient in the preceding year. If not, they were asked to return the uncompleted survey. Data were anonymously entered into a RedCap database and exported to the SAS System, version 9.2 (Cary, NC, USA) for analysis. This study was approved by the University of Michigan Institutional Review Board.

\section{Measures}

The questionnaire was developed after a literature review and search for existing measures where available. Next, we employed an iterative design process and standard techniques of content validation, including systematic review of questions by content matter experts and experts in survey design. Instrument refinement also included cognitive pre-testing with surgeons and medical oncologists outside our target sample. 


\section{Dependent measures}

Confidence in presenting risk information, identifying women with high levels of worry, and managing worries about recurrence: Clinician confidence in their ability to (a) present risk information to a breast cancer survivor in a way they will understand, (b) identify breast cancer survivors with high levels of worry, and (c) help breast cancer survivors manage their worries surrounding recurrence was assessed on 5-point Likert-type scales with endpoints labeled 'not at all confident' and 'extremely confident.' For purposes of analysis, we collapsed the responses into two categories: $<4$ was considered 'not confident', and $\geq 4$ was considered 'confident'.

Initiate discussions on worry: Respondents were asked whether they routinely initiated discussions regarding worry about recurrence with the breast cancer patients who did not bring up the issue themselves (yes/no).

Strategies used to manage worry: We inquired about the likelihood that physicians would use nine different strategies if their patient appeared very worried about the likelihood of her cancer returning. The strategies included 'address her concerns in detail yourself', 'encourage her to join a cancer support group', 'schedule follow-up visits more frequently', and 'prescribe medications', among others (Table 2). Responses were on a 4-point Likert-type scale ranging from 'definitely no' to 'definitely yes'. For purposes of analysis, we collapsed the response options into two categories: 'definitely no' and 'probably no' were collapsed into 'no', and 'probably yes' and 'definitely yes' were collapsed into 'yes'.

\section{Independent measures}

Provider and practice characteristics: Provider characteristics assessed included gender (male/female), race/ ethnicity (White/Caucasian, Black/African American, Hispanic/Latino, Arab or Arab American, American Indian or Alaska Native, Asian or Pacific Islander, and other; collapsed during analysis to White, Asian or Pacific Islander, other), age, and years since completing residency. Practice characteristics included whether the practice includes residents or fellows (yes/no), whether the practice arranged same-day appointment with other clinicians/specialists (yes/no), number of newly diagnosed women seen in the past year $(\leq 10,11-20,21-50, \geq 51)$. Clinicians also were asked to indicate the percentage of early stage breast cancer patients they followed for: (a) no more than 1 year, (b) between 1 and 3 years, (c) more than 3 years, or (d) more than 5 years after completion of therapy (collapsed during analysis into $\leq 3$ years vs $>3$ years).

\section{Analysis plan}

We described the study sample by demographic and practice characteristics and then generated descriptive statistics for the three groups of variables of interest: providers' confidence in presenting risk information, their assessment of their patients' understanding of their recurrence risk, and the providers' strategies to help their patients' manage worry about recurrence. We tested for the significance of observed differences between surgeons and medical oncologists using the chi-square statistic and Student's $t$-test for categorical and continuous data, respectively.

We further developed multiple variable logistic regression models to explain confidence in presenting risk, assessing and managing worry, and the odds of using the nine strategies for the management of worry about recurrence (yes/no). For example, the probability of use of each strategy was modeled separately with the provider specialty (oncologist or surgeon) as the primary independent variable after controlling for provider gender, time in practice, patient volume, having residents or fellows, whether same-day appointments are scheduled for patients with other breast cancer specialists, and the duration of clinical follow-up for patients. Full models that included all covariates simultaneously are reported. For all statistical tests, $p$-values $\leq 0.05$ were considered significant.

\section{Results}

We received a total of 896 responses, a $60.5 \%$ response rate after adjusting for 17 surveys returned because of invalid addresses and two physicians who had retired. Of the respondents, 130 reported that they did not see any new breast cancer patients in the last 12 months. The remaining 766 respondents constituted our analytical sample: 403 surgeons and 363 medical oncologists. Table 1 displays the physician demographic and practice setting characteristics. The majority of the sample was male $(79.2 \%)$ and White $(73.6 \%)$. The mean age was 52 years. A greater proportion of surgeons compared with medical oncologists were male $(85.0 \%$ vs $72.7 \%$; $p$-value $<0.001)$, White $(81.0 \%$ vs $65.3 \%$; $p$-value $>0.001)$, and older (53 years compared with 51 years, $p=0.014$ ).

About a quarter of those surveyed saw less than 10 newly diagnosed patients in the past year, with another $50 \%$ who saw between 11 and 50 patients, and slightly less than a quarter who saw more than 50 newly diagnosed patients in the past year. Significant differences by provider type were noted with $16 \%$ of surgeons versus $30 \%$ of medical oncologists reported seeing more than 50 new breast cancer patients within the past 12 months $(p<0.001)$. Most of the survey respondents $(74.8 \%)$ reported following the majority of their patients for 3 years or more compared with $25.2 \%$ who reported seeing patients for less than 3 years. Approximately, $56 \%$ of surgeons reported following the majority of 
Table I. Provider and practice characteristics

\begin{tabular}{|c|c|c|c|c|}
\hline & Total & Surgeons & Medical oncologists & $\overline{p \text {-value }}$ \\
\hline \multicolumn{5}{|l|}{ Provider characteristics ${ }^{\mathrm{a}}$} \\
\hline \multicolumn{4}{|l|}{ Gender: N (\%) } & \multirow[t]{2}{*}{$<0.00$ । } \\
\hline Male & $598(79.2)$ & $340(85.0)$ & $258(72.7)$ & \\
\hline \multicolumn{4}{|l|}{ Race: $N(\%)$} & \multirow[t]{3}{*}{$<0.00$ । } \\
\hline White & $550(73.6)$ & $320(81.0)$ & $230(65.3)$ & \\
\hline Asian or Pacific Islander & $132(17.7)$ & $39(9.8)$ & $93(26.4)$ & \\
\hline Years since completing residency: mean (SD) [min.-max.] & $19(10)[1.5-45]$ & $20(9)[|.5-4|]$ & $18(10)[1.5-45]$ & 0.005 \\
\hline \multicolumn{5}{|l|}{ Practice characteristics } \\
\hline \multicolumn{4}{|l|}{ Residents or fellows } & \multirow[t]{3}{*}{0.292} \\
\hline Yes & $193(25.3)$ & $108(26.9)$ & $85(23.5)$ & \\
\hline No & $570(74.7)$ & $294(73.1)$ & $276(76.5)$ & \\
\hline \multicolumn{2}{|c|}{ Same-day appointments available to meet with clinician specialists } & & & 0.672 \\
\hline $11-20$ & $167(21.9)$ & $99(24.6)$ & $68(18.8)$ & \multirow{3}{*}{$<0.001$} \\
\hline $21-50$ & $227(29.7)$ & $97(24.1)$ & $130(35.9)$ & \\
\hline$>50$ & $170(22.2)$ & $63(15.7)$ & $107(29.6)$ & \\
\hline \multicolumn{2}{|l|}{ Majority of cases followed for $>3$ years } & & & \multirow[t]{3}{*}{$<0.00$ I } \\
\hline No: N (\%) & I 88 (25.2) & $165(42.1)$ & $23(6.5)$ & \\
\hline Yes: N (\%) & $557(74.8)$ & $227(57.9)$ & $330(93.5)$ & \\
\hline
\end{tabular}

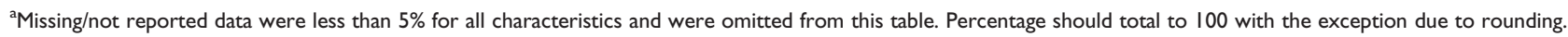

their patients greater than 3 years compared with over $90 \%$ of medical oncologists $(p<0.001)$.

Figure 1 displays the percent of respondents who indicated that they were confident in presenting risk information, identifying women who were worried about recurrence, and managing patients' worry. Overall, both surgeons and medical oncologists more often reported having confidence in presenting risk, followed by identifying women who have worry, and then helping women manage worry about recurrence. Medical oncologists were significantly more likely to report confidence in presenting risk information compared with surgeons $(87.5 \%$ and $73.2 \%, p<0.001)$. About $74 \%$ of medical oncologists reported being confident in identifying women who are worried compared with approximately $64 \%$ of surgeons $(74.1 \%$ vs $63.9 \%, p=0.002)$. A similar pattern was seen with physician confidence in managing worry. Approximately, $67 \%$ of medical oncologists were confident in their ability to manage worry compared with just over $50 \%$ of surgeons $(66.9 \%$ vs $52.4 \%, p<0.001)$.

About $60 \%$ of respondents reported routinely initiating discussions regarding worry about recurrence with their patients who themselves do not bring up the issue, with no statistically significant differences found between provider type. A significant association was found between those who regularly initiated discussions and their confidence in their ability to manage worry $(p=0.009)$. About $62 \%$ of those reporting they routinely initiate discussion regarding worry about recurrence reported confidence in their ability to help breast cancer survivors manage worry, whereas only about $53 \%$ who do not routinely inquire about worry reported being confident about managing worry.

When we modeled the three domains of confidence (i.e., presenting risk information, identifying survivors with high levels of worry, and managing worry about recurrence) by provider and practice characteristics, there were a number of significant relationships that emerged. Medical oncologists were more likely than surgeons to report confidence in presenting risk information (odds ratio $(\mathrm{OR})=1.92,95 \% \mathrm{CI} 1.25-2.99)$ and in managing survivors worry about recurrence $(\mathrm{OR}=1.66$, 95\% CI 1.18-2.34). Across clinician characteristics, female compared with male physicians were more likely to report confidence in identifying survivors with high levels of worry $(\mathrm{OR}=2.71,95 \%$ CI 1.67-4.57). Among practice characteristics, providers with larger patient volumes (i.e., having seen greater than 20 breast cancer patients in the last 12 months vs 20 or less such patients) were more likely to report confidence in presenting risk information $(\mathrm{OR}=1.92$, 95\% CI 1.28-2.89) and in identifying survivors with high levels of worry (OR 1.92, 95\% CI 1.36-2.72). Finally, providers in practices that offer same-day appointments with different specialists versus those practices who do not were more likely to report confidence in managing women's worry about recurrence $(\mathrm{OR}=1.76,95 \%$ CI 1.28-2.41). No significant relationships were found between reported confidence across the three domains and provider time in practice, availability of residents and fellows in practice, or length of clinical follow-up. 


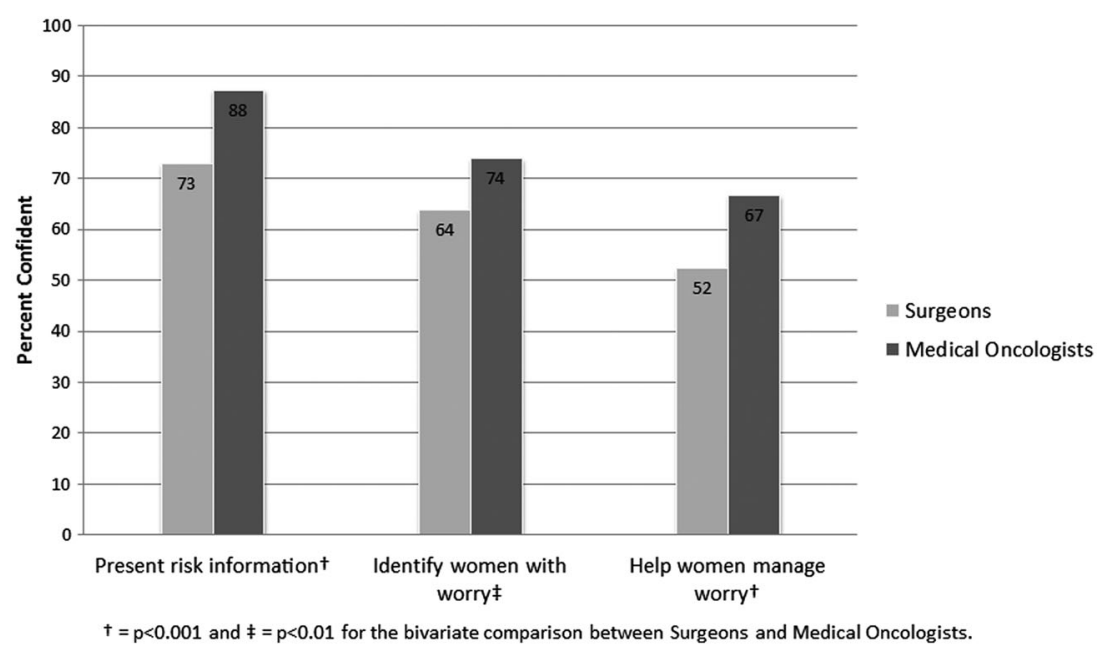

Figure I. Percent physicians confident in presenting risk, identifying women with worry, and managing worry about recurrence, by provider type

Figure 2 displays the frequency with which surgeons and medical oncologists reported that they would use each of several potential strategies for managing worry about recurrence, from the most to least frequently used across both provider types. Overall, the strategies endorsed most frequently included addressing the concerns themselves and encouraging the women to join a cancer support group. Surgeons were more likely than medical oncologists to recommend joining a support group or offer reading material, whereas medical oncologists were more likely to suggest alternative therapies, make referrals to a psychologist or social worker, and prescribe medication.

Table 2 presents the associations when modeling the use of potential strategies to manage worry by a number of provider and practice characteristics. Significant differences remained by provider type (surgeon versus medical oncologist) as seen in Figure 2, even when controlling for all other provider and practice factors. Other noted differences included that female (compared with male) physicians were more likely to report referring women to a psychologist/ social worker and recommending alternative therapies. Providers who had been in practice longer were less likely to encourage their patients to get involved in peer counseling and to prescribe medication. Practice characteristics such as patient volume and the availability of residents and fellows influenced the likelihood of using referrals and alternative therapies. Physicians who reported following most of their patients longer were more likely to address patient concerns themselves compared with those who followed patients for less time.

\section{Discussion}

Although addressing worry about recurrence is an important need of breast cancer survivors [1-7], little research has focused on physicians' behaviors and perspectives

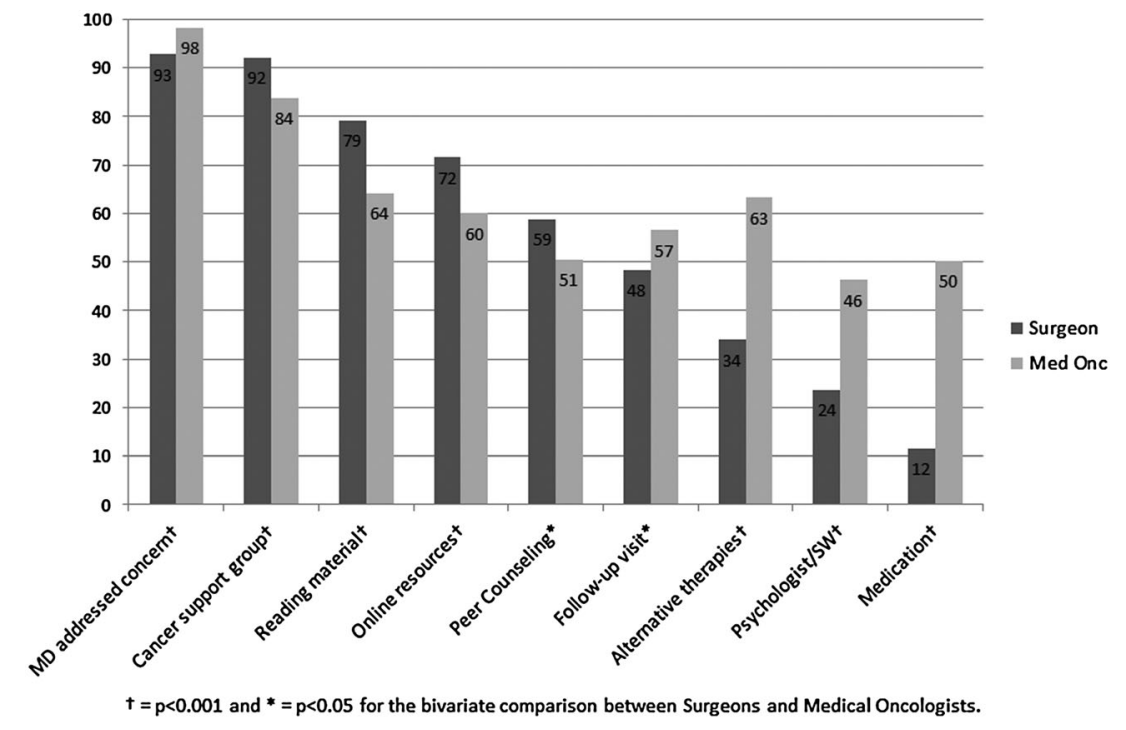

Figure 2. Strategies used to manage worry about recurrence, by provider type 


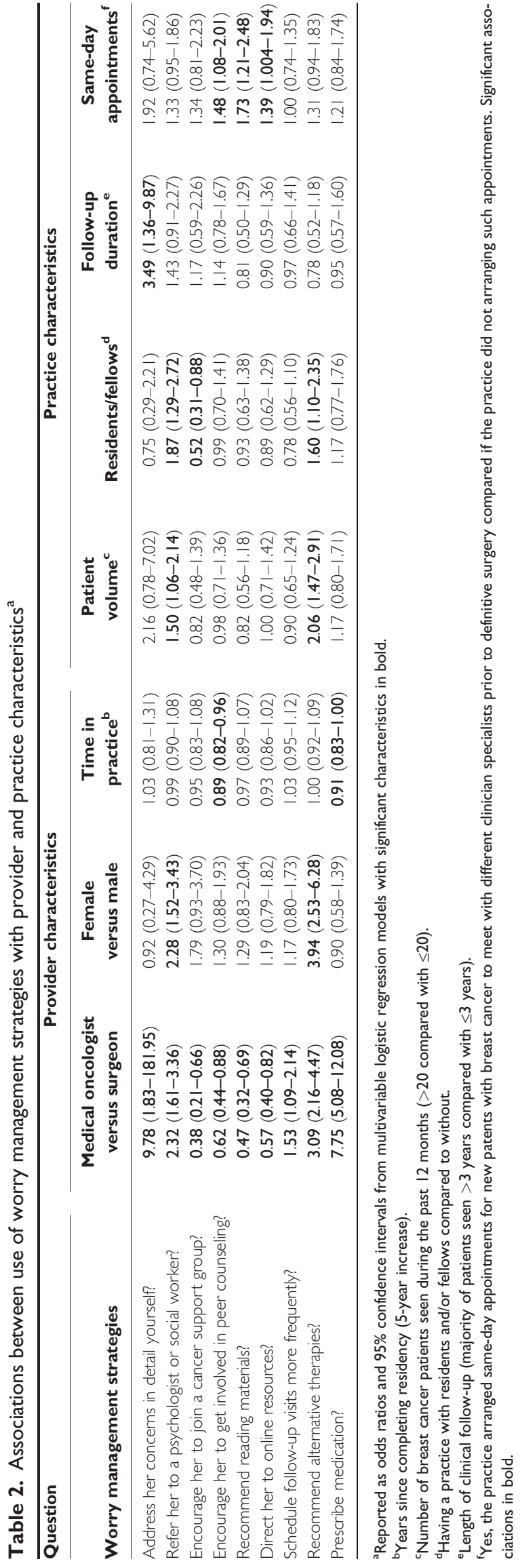

regarding assessing and managing women's concerns about cancer recurrence $[14,15,32]$. Our findings suggest that most surgeons and medical oncologists feel confident presenting risk information, confidence which may or may not be justified given the evidence of patient confusion about such communications [21,33]. However, these same clinicians appear somewhat less confident in identifying women who are worried and report being the least confident in managing patients' worry about recurrence. It was somewhat troubling that almost half of the surgeons in our sample expressed medium/low confidence in their ability to help women manage their worries about recurrence. In addition, we found that when women are identified who express high levels of worry about recurrence, the strategies employed to manage their concerns differed considerably between surgeons and medical oncologists.

Cancer patients want their provider team to ask about and to help manage their psychosocial concerns, as many patients may be reluctant to raise emotional distress themselves unless invited to do so [32,34-36]. Detmar et al. (2000) [32] found that although $94 \%$ of patients wanted to discuss emotional functioning with their doctors, $39 \%$ would do so only if the physician initiated the discussion. Another factor that may influence whether some physicians' inquire about worry about recurrence is an assumption that other cancer providers or health team members are managing these emotional needs [30]. Clearly, discordant expectations about who is responsible for initiating discussions may contribute to gaps in survivorship care [37-39].

Routinely assessing all breast cancer survivors about worry is needed to capture those who exhibit considerable worry despite rather low actual risk of recurrence [2,40-42]. Our findings suggest that about $40 \%$ of physicians surveyed do not routinely inquire about worry, and those with less confidence in managing worry were less likely to report routine assessments. These represent missed clinical opportunities to assess the psychosocial needs of cancer survivors and provide appropriate supportive care for those in need. In addition, physicians frequently fail to detect their patients' distress accurately [16,43-45], most often under-estimating the level of distress [46]. Focused seminars, online webinars, and/or training opportunities are needed to raise the level of confidence among some cancer providers in assessing worry [30]. Surgeons and providers seeing fewer breast cancer patients in their practice may benefit from targeted skills training.

Providers also may find the use of validated measures to assess worry about recurrence beneficial. A recent review of distress screening tools in cancer concluded that few have been compared with one another but that use of tools seems to improve communication between patients and providers and may enhance psychosocial referrals [47]. In one study where oncologists were provided with a summary of patients' quality-of-life assessments before a consultation, patients received more counseling on how to manage 
problems [32]. Validated measures assessing worry need to provide guidelines for interpretation of clinically meaningful scores that indicate the need for intervention, such as referral to a mental health professional [8]. The current tools for evaluating fears about cancer recurrence are underutilized. A systematic review identified a total of 20 relevant multi-dimensional instruments measuring fear of cancer recurrence, 10 of which were brief measures (containing between 2 and 10 items) that would be suitable for use in a clinical setting [48]. Additionally, several of these brief measures were developed specifically for use with breast cancer patients [49-51]. Further studies should evaluate the efficacy of using brief measures in the clinical setting as a means of identifying women with enhanced worry in need of supportive care.

Managing worry about recurrence may require a coordinated approach that enlists the services of multiple care providers and employs a variety of strategies tailored to the setting and the need of the individual patient. Although we found that the use of strategies differed primarily by provider type, some characteristics of the practice setting such as volume, availability of residents/fellows, and/or sameday appointments for patients can influence the supportive services offered. As expected, providers that followed their patients longer had more opportunities to monitor worry and were more likely to endorse addressing a woman's worry about recurrence concerns in detail themselves. Over $90 \%$ of medical oncologists followed their patients more than 3 years, but we found differences by specialty even on multivariable analysis that controlled for duration of follow-up, so we believe these differences in addressing worry merit attention. Differences in the nature of training, normative disciplinary expectations surrounding patient care and follow-up, and personality types of typical surgeons versus oncologists may also be important. For example, medical oncologists may be more comfortable with both patient counseling and pharmacologic interventions than surgeons. Greater understanding of the influence of physicians' personal qualities, goals, and/or external circumstances that can impact interactions with cancer patients is needed [36,52]. In addition, more empirical studies are needed to assess the relative benefit of interventions to reduce worry and in what circumstances one strategy may be more beneficial than another (online versus cognitive behavioral approaches versus support groups) $[8,53]$.

Our study has a number of strengths, including a relatively high response rate from a national sample of medical oncologists and surgeons who were selected solely on the basis of having seen at least one new breast cancer case in the preceding year. Limitations include self-report about confidence and that behavior reported could be subject to bias relating to recall, or social desirability. In addition, the nine strategies assessed for managing worry about recurrence were not exhaustive and, for example, did not capture referrals to mental health professionals such as a nurse practitioner or psychiatrist. Further studies should focus on a more in-depth examination of various strategies and referral patterns and how they may differ by access and health system factors. Although not within the scope of this study, it would be useful to determine if surgeons and oncologists are aware of resources and support services available at their institutions or within their communities, and the extent to which they utilize these resources.

In summary, given the Institute of Medicine's recognition that psychosocial care is integral to quality survivorship care [13] further attention needs to be devoted to assessing psychological well-being, recognizing women in distress, and managing women with excessive worry about recurrence. Strategies to manage distress need to be more carefully evaluated across diverse populations and time since diagnosis. Survivorship care plans could provide a vehicle for communication between care providers and the patient [53]. Models of care coordination [54] must be developed and assessed to increase the likelihood that psychological distress such as worry about recurrence is being recognized and addressed.

\section{Acknowledgements}

This study was supported in part by a mentored research scholar grant from the American Cancer Society (MRSG-09-145-01) awarded to Dr. Reshma Jagsi.

\section{Conflict of interest}

There is no conflict of interest noted among any of the corresponding authors.

\section{References}

1. van den Beuken-van Everdingen $M H$, Peters ML, de Rijke JM, Schouten HC, van Kleef M, Patijn J. Concerns of former breast cancer patients about disease recurrence: a validation and prevalence study. Psycho-Oncology 2008;17:1137-1145. doi: 10.1002/pon.1340.

2. Vickberg SM. The concerns about recurrence scale (CARS): a systematic measure of women's fears about the possibility of breast cancer recurrence. Ann Behav Med 2003; 25:16-24.
3. Lebel S, Rosberger Z, Edgar L, Devins GM. Emotional distress impacts fear of the future among breast cancer survivors not the reverse. $J$ Cancer Surviv 2009;3:117-127. doi: 10.1007/s11764-009-0082-5.

4. Baker F, Denniston M, Smith T, West MM. Adult cancer survivors: how are they faring? Cancer 2005;104:2565-2576.

5. Kornblith AB, Powell M, Regan MM, et al. Long-term psychosocial adjustment of older vs. younger survivors of breast and endometrial cancer. Psycho-Oncology 2007;16: 895-903.
6. Deimling GT, Bowman KF, Sterns S, Wagner LJ, Kahana B. Cancer-related health worries and psychological distress among older adult, long-term cancer survivors. Psycho-Oncology 2006;16:306-320.

7. Simard S, Thewes B, Humphris G, et al. Fear of cancer recurrence in adult cancer survivors: a systematic review of quantitative studies. $J$ Cancer Surviv 2013;7(3):300-322.

8. Koch L, Bertram H, Eberle A, et al. Fear of recurrence in long-term breast cancer survivors-still an issue. Results on prevalence, determinants, and the association with 
quality of life and depression from the Cancer Survivorship-a multi-regional populationbased study. Psycho-Oncology 2014;23: $547-554$.

9. Hawley ST, Griggs JJ, Hamilton AS, et al. Decision involvement and receipt of mastectomy among racially and ethnically diverse breast cancer patients. J Natl Cancer Inst 2009;101:1337-1347. doi: 10.1093/jnci/ $\operatorname{djp} 271$.

10. Katz SJ, Lantz PM, Janz NK, et al. Patient involvement in surgery treatment decisions for breast cancer. J Clin Oncol 2005;23: 5526-5533.

11. McGuire KP, Santillan AA, Kaur P, et al. Are mastectomies on the rise? A 13-year trend analysis of the selection of mastectomy versus breast conservation therapy in 5865 patients. Ann Surg Oncol 2009;16:2682-2690. doi: 10.1245/s10434-009-0635-x.

12. Janz NK, Hawley ST, Mujahid MS, et al. Correlates of worry about recurrence in a multiethnic population-based sample of women with breast cancer. Cancer 2011;117: 1827-1836. doi: 10.1002/cncr.25740.

13. Hewitt M, Greenfield S, Stovall E. From Cancer Patient to Cancer Survivor: Lost in Transition. The National Academy Press: Washington, DC; 2006.

14. Grunfeld E, Levine MN, Julian JA, et al. Randomized trial of long-term follow-up for early-stage breast cancer: a comparison of family physician versus specialist care. J Clin Oncol 2006;24:848-855.

15. Forsythe LP, Alfano CM, Leach CR, et al. Who provides psychosocial follow-up care for post-treatment cancer survivors? A survey of medical oncologists and primary care physicians. J Clin Oncol 2012;30:2897-2905. doi: $10.1200 / J C O .2011 .39 .9832$.

16. Fallowfield L, Ratcliffe D, Jenkins V, Saul J. Psychiatric morbidity and its recognition by doctors in patients with cancer. Br J Cancer 2001;84:1011.

17. Del Giudice ME, Grunfeld E, Harvey BJ, Piliotis E, Verma S. Primary care physicians' views of routine follow-up care of cancer survivors. J. Clin. Oncol. 2009;27:3338-3345. doi: 10.1200/JCO.2008.20.4883.

18. Zikmund-Fisher BJ, Fagerlin A, Ubel PA. Improving understanding of adjuvant therapy options by using simpler risk graphics. Cancer 2008;113:3382-3390. doi: 10.1002/ cncr.23959.

19. Peele PB, Siminoff LA, Xu Y, Ravdin PM. Decreased use of adjuvant breast cancer therapy in a randomized controlled trial of a decision aid with individualized risk information. Med Decis Making 2005;25: 301-307.

20. Siminoff LA, Gordon NH, Silverman P, Budd T, Ravdin PM. A decision aid to assist in adjuvant therapy choices for breast cancer. PsychoOncology 2006;15:1001-1013.

21. Lipkus IM, Peters E, Kimmick G, Liotcheva V, Marcom P. Breast cancer patients' treatment expectations after exposure to the decision aid program adjuvant online: the influence of numeracy. Med Decis Making 2010;30:464-473. doi: 10.1177/ 0272989X09360371.

22. Belkora JK, Hutton DW, Moore DH, Siminoff LA. Does use of the Adjuvant! model influence use of adjuvant therapy through better risk communication? J Natl Compr Canc Netw 2011;9:707-712.

23. Forsythe LP, Kent EE, Weaver KE, et al. Receipt of psychosocial care among cancer survivors in the United States. J. Clin. Oncol. 2013;31(16):1961-1969.

24. Robbins JM, Kirmayer LJ, Cathebras P, Yaffe MJ, Dworkind M. Physician characteristics and the recognition of depression and anxiety in primary care. Med Care 1994;32(8): 795-812.

25. Passik SD, Dugan W, McDonald MV, et al. Oncologists' recognition of depression in their patients with cancer. J. Clin. Oncol. 1998;16(4): 1594-1600.

26. Werner A, Stenner C, Schuz J. Patient versus clinician symptom reporting: how accurate is the detection of distress in the oncologic after-care? Psycho-Oncology 2012;21: 818-826.

27. Husson O, Mols F, van de Poll-Franse LV. The relation between information provision and health-related quality of life, anxiety and depression among cancer survivors: a systematic review. Ann Oncol 2011;22(4): 761-772.

28. Moyer A, Sohl SJ, Knapp-Oliver, SK, Schneider S. Characteristics and methodological quality of 25 years of research investigating psychosocial interventions for cancer patients. Cancer Treat Rev 2009;35: 475-484. doi: 10.1016/j.ctrv.2009.02.003.

29. Clanton J, Gardner JA, Cheung M, et al. The relationship between confidence and competence in the development of surgical skills. J Surgical Educ 2014;71(3): 405-412.

30. Forsythe LP, Alfano CM, Leach CR, et al. Who provides psychosocial follow-up care for post-treatment cancer survivors? A survey of medical ocologists and primary care physicians. J. Clin. Oncol. 2012;30(23): 2897-2905.

31. Dillman DA. Mail and Telephone Surveys: The Total Design Method. John Wiley \& Sons: New York, 1978.

32. Detmar SB, Aaronson NK, Weaver LDV, et al. How are you feeling? Who wants to know? Patients and oncologists' preferences for discussing health related qualityof-life issues. $J$ Clin Oncol 2000;18:3 295-3301.

33. Belkora J, Rugo HS, Moore DH, Hutton D, Esserman L. Risk communication with patients with breast cancer: cautionary notes about printing Adjuvant! estimates. Lancet Oncol 2008;9:602-603. doi: 10.1016/S14 70-2045(08)70158-X.
34. Audit Commission. What seems to be the matter? Communication between hospitals and patients. NHS Report No. 12, HMSO, 1993.

35. Fallowfield L, Jenkins V. Effective communication skills are the key to good cancer care. Eur J Cancer 1999;35:1592-1597.

36. Hack TF, Degner LF, Parker PA. The communication goals and needs of cancer patients: a review. Psycho-Oncology 2005;14: 831-845.

37. Cheung WY, Neville BA, Cameron DB, Cook EF, Earle CC. Comparisons of patient and physician expectations for cancer survivorship care. J Clin Oncol 2009;27: 2489-2495. doi: 10.1200/JCO.2008.20.3232.

38. Earle CC, Burstein HJ, Winer EP, et al. Quality of non-breast cancer health maintenance among elderly breast cancer survivors. J Clin Oncol 2003;21:1447-1451.

39. Earle CC, Neville BA. Under use of necessary care among cancer survivors. Cancer 2004;101: 1712-1719.

40. Costanzo ES, Lutgendorf SK, Mattes ML, et al. Adjusting to life after treatment: distress and quality of life following treatment for breast cancer. Br J Cancer 2007;97(12):1625-1631.

41. Mellon S, Kershaw TS, Northouse LL, Freeman-Gibb L. A family-based model to predict fear of recurrence for cancer survivors and their caregivers. Psycho-Oncology 2007;16: 214-223.

42. Mathews A, Ridgeway V, Warren R, Britton P. Predicting worry following a diagnosis of breast cancer. Psycho-Oncology 2002;11:415-418.

43. Merckaert I, Libert Y, Delvaux N, et al. Factors that influence physicians' detection of distress in patients with cancer. Cancer 2005; 104:411-421.

44. Söllner W, DeVries A, Steixner E, et al. How successful are oncologists in identifying patient distress, perceived social support, and need for psychosocial counseling? $\mathrm{Br}$ $J$ Cancer 2001;84:179. doi: 10.1054/ bjoc. 2000.1545.

45. Newell S, Sanson Fisher RW, Girgis A, Bonaventura A. How well do medical oncologists' perceptions reflect their patients' reported physical and psychosocial problems? - Data from a survey of five oncologists. Cancer 1998;83:1640-1651.

46. Ford S, Fallowfield LJ, Lewis S. Can oncologists detect distress in their out-patients and how satisfied are they with their performance during bad news consultations? Br J Cancer 1994;70:767.

47. Carlson LE, Waller A, Mitchell AJ. Screening for distress and unmet needs in patients with cancer: review and recommendations. J Clin Oncol 2012;30:1160-1177. doi: 10.1200/ JCO.2011.39.5509.

48. Thewes B, Butow P, Zachariae R, et al. Fear of cancer recurrence: a systematic literature review of self-report measures. PsychoOncology 2012;21(6):571-587.

49. Easterling DV, Leventhal H. Contribution of concrete cognition to emotion: neutral 
symptoms as elicitors of worry about cancer. $J$ Appl Psychol 1989;74(5):787.

50. Lasry JCM, Margolese RG. Fear of recurrence, breast-conserving surgery, and the trade-off hypothesis. Cancer 1992;69(8):2111-2115.

51. Rabin C, Leventhal H, Goodin S. Conceptualization of disease timeline predicts posttreatment distress in breast cancer patients. Health Psychol 2004;23(4):407.

52. Merchaert I, Libert Y, Delvaux N, et al. Factors that influence physicians' detection of distress in Patients with cancer - can a communication skills training program improve physicians' detection? ACS 2005;104(2):411-421.
53. Stanton AL. Psychosocial concerns and interventions for cancer survivors. J Clin Oncol 2006; 24:5132-5137.

54. Lewis RA, Neal RD, Williams $\mathrm{NH}$, et al. Follow-up of cancer in primary care versus secondary care: systematic review. $\mathrm{Br} J \mathrm{Gen}$ Pract 2009;59(564):e234-e247. 